\title{
A tribute to John Carey: 09 March 1935 - 14 May 2015
}

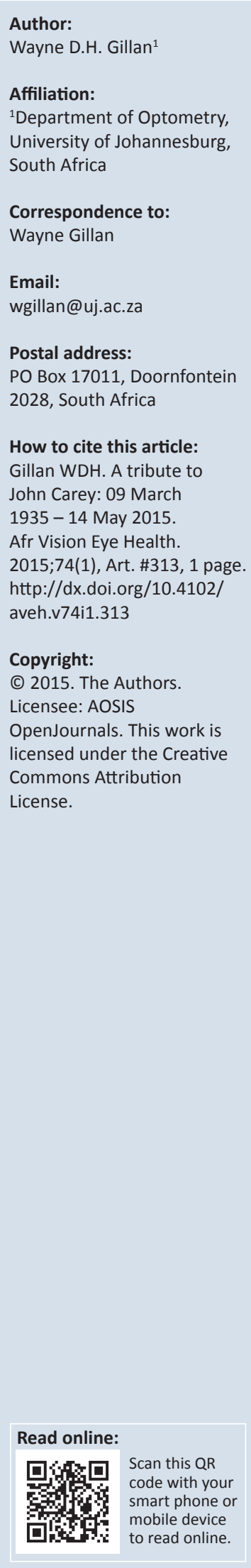

South African optometry lost one of its more prominent citizens with the passing of John Michael Carey on Thursday 14 May 2015. John will be remembered for numerous contributions to our profession. For many years, he produced the popular Carey's Corner, initially published in the South African Optometrist and later continued in the Eyesite magazine. John was always able to produce clinical cases that stimulated thought and introspection on the part of the reader. Of course, there was always some new piece of information that he had read somewhere that he presented to his readers for them to ponder. Every one of his corners ended with 'Isn't optometry exciting?' John was the chairman of the Binocular Vision Association for many years and, under his leadership, numerous congresses were arranged, much to the benefit of all those who attended. Many a RAU optometry student will remember his favourite trick: 'interogattione'. Here, a student was expected to answer questions relating to John's last lecture, and marks would be awarded for the student's efforts. Whilst students did not appreciate this form of torture, I am sure that they all benefited by the revision that they were forced to do in preparation. John recently acted as ombudsman for Preferred Provider Negotiators (PPN) and only ended his association with that company six months prior to his death. Whilst not everyone might have agreed with him, one cannot question his dedication to the profession that he loved.

John's death creates a void that will be difficult to fill. He leaves his wife Janet and her family, and his ex-wife Dorothy, their five children and ten grandchildren. John will be missed by all who interacted with him. My condolences go to his family.

May he rest in peace.

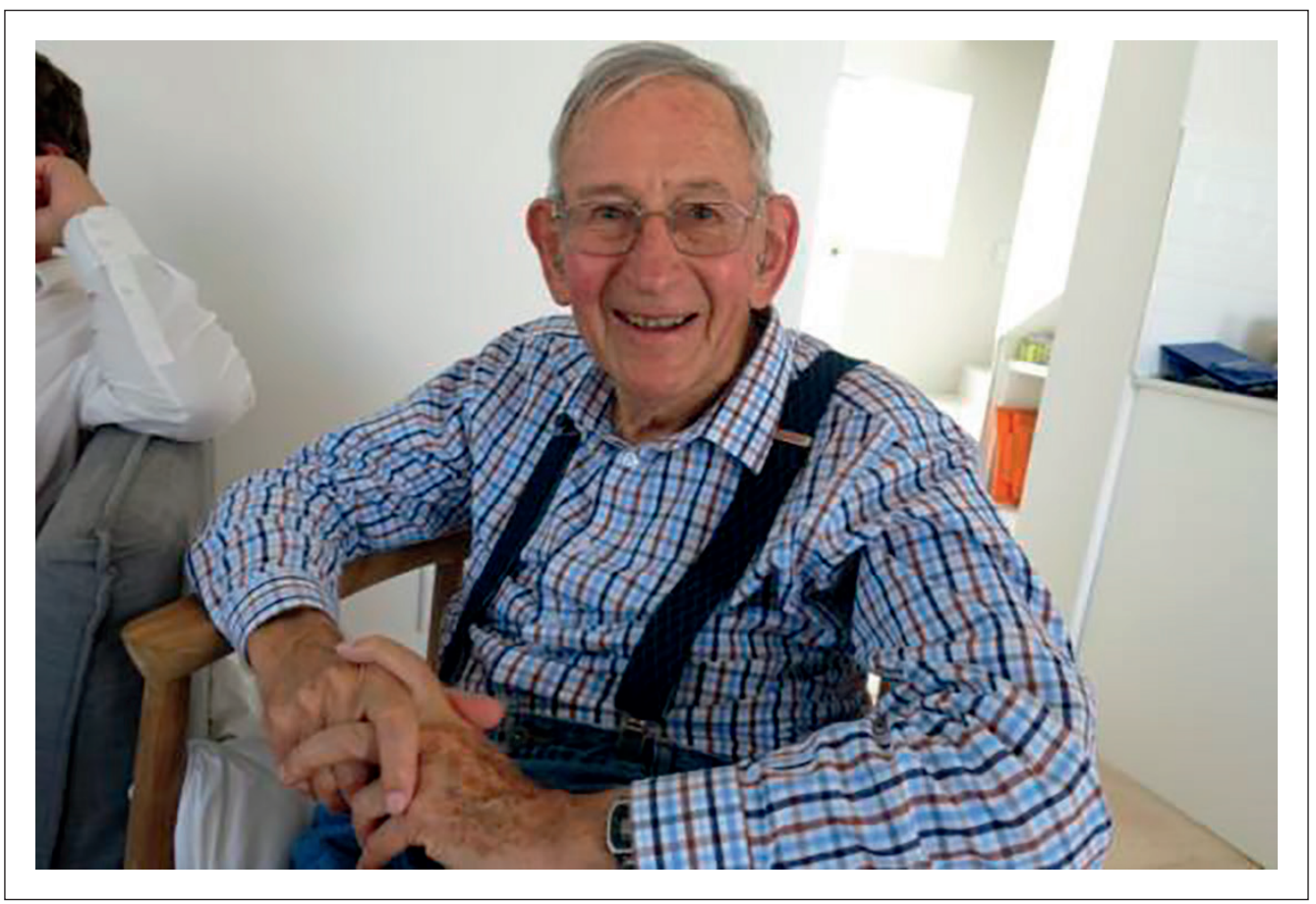

Photo: Susan Liebenberg

John in jovial mood during birthday celebrations with his family. 